\title{
Records of Environmental Changes in the Australian Sector of Pep II Point to Broad Trends of Climate Change
}

\section{Patrick De DeckKer}

Australian National University, Canberra, Australia. patrick.dedeckker@anu.edu.au

For more than 2 decades, much effort has been geared toward understanding conditions that existed in the Australian region at the Last Glacial Maximum (LGM) around 20,000 years ago. More recently, researchers have increasingly focused on identifying patterns and amplitude of climatic change since the LGM.

The excess of evaporation over precipitation, characteristic of a vast portion of Australia, renders it difficult to find lacustrine deposits suitable for the recovery of archives of environmental change. The search of such archives has thus forced researchers to investigate sites offshore in order to determine patterns and amplitudes of environmental change on the Australian continent. A core from one such site, located offshore of the north western tip of Western Australia, some $60 \mathrm{~km}$ from Cape Range provides a multi- proxy 30, 000 year record. Results are presented in Figure 1. The $\delta^{180}$ record of planktonic foraminifers not only indicates a progressive sealevel rise since the LGM, but also significant fluctuations during the Holocene. These later variations result from an influx of low-salinity Pacific water via the Indonesian throughflow. This variability was intensified as a result of monsoonal activity, which commenced in the region around 14 ky ago as indicated by a decrease in the carbonate content in the core associated with the influx of terrestrial clays brought to the coring site by fluvial waters. The onset of monsoon activity is confirmed by an increase in aquatic pollen content. Mean seasurface temperature reconstructed from foraminifer faunal analyses is surprisingly high at $11 \mathrm{ky}$, and shows a definite downward trend for the last $5 \mathrm{k}$ years. This record also shows

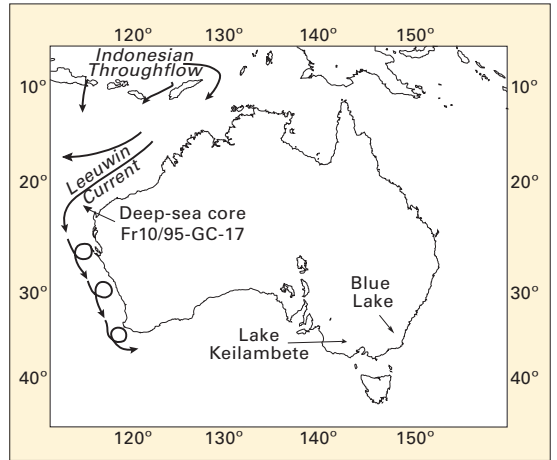

a peak in fluvial discharge indicated by decreased carbon content and aquatic pollen changes between 8 and $7 \mathrm{ky}$. Conditions in the water column above the site are also indicated by the ratio of nannoplankton taxa $G$. flabellata and $A$. robusta (which live in the middle to the lower part of the euphotic zone) to $F$ profunda [which occur in high concentration in the euphotic zone]. The presence of pteridophyte spores in the upper

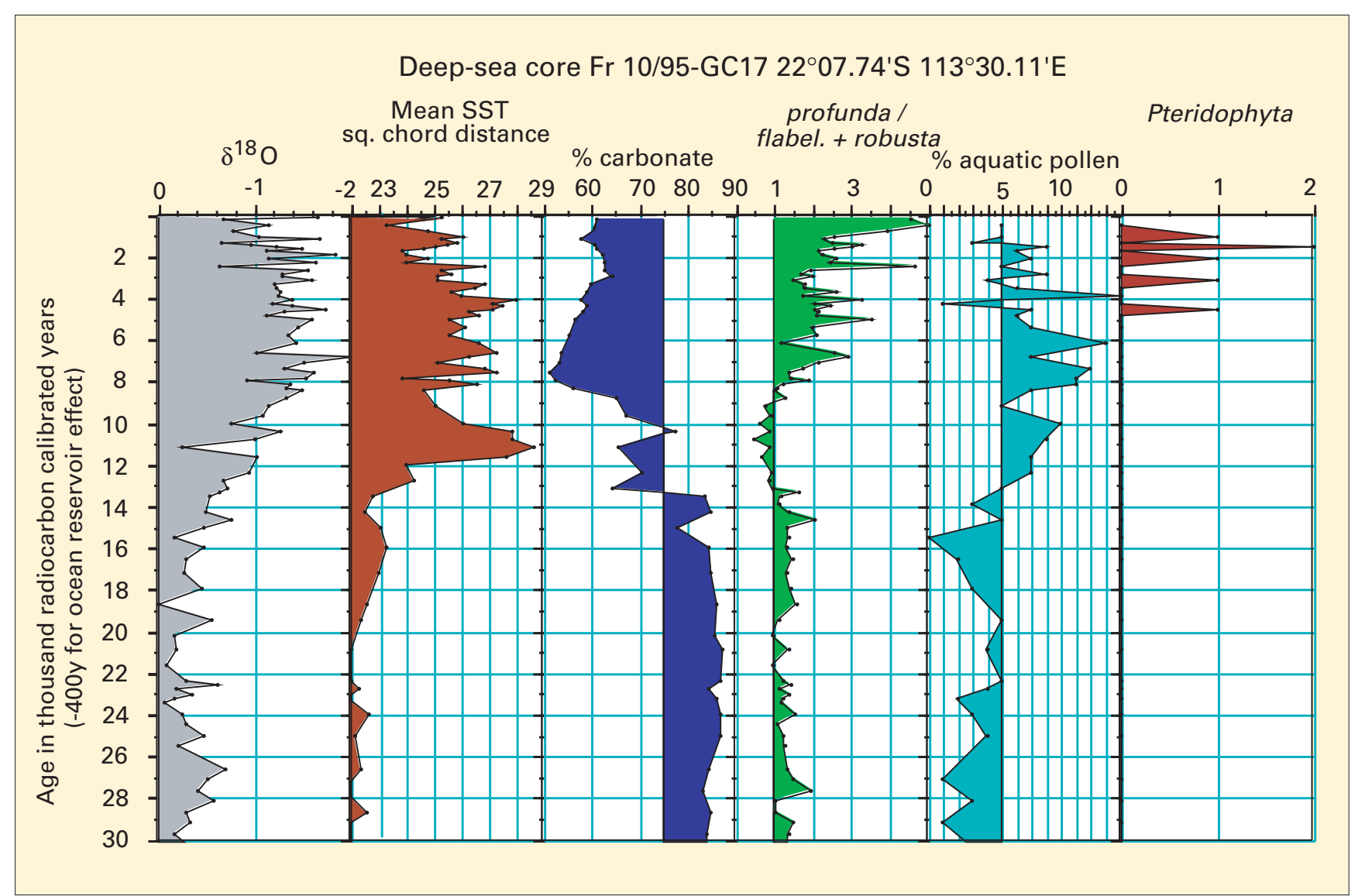

Fig. 1. Multiple lines of proxy environmental and climatic information from a marine core offshore of the northwestern tip of Western Australia 


\title{
Science Highlights
}

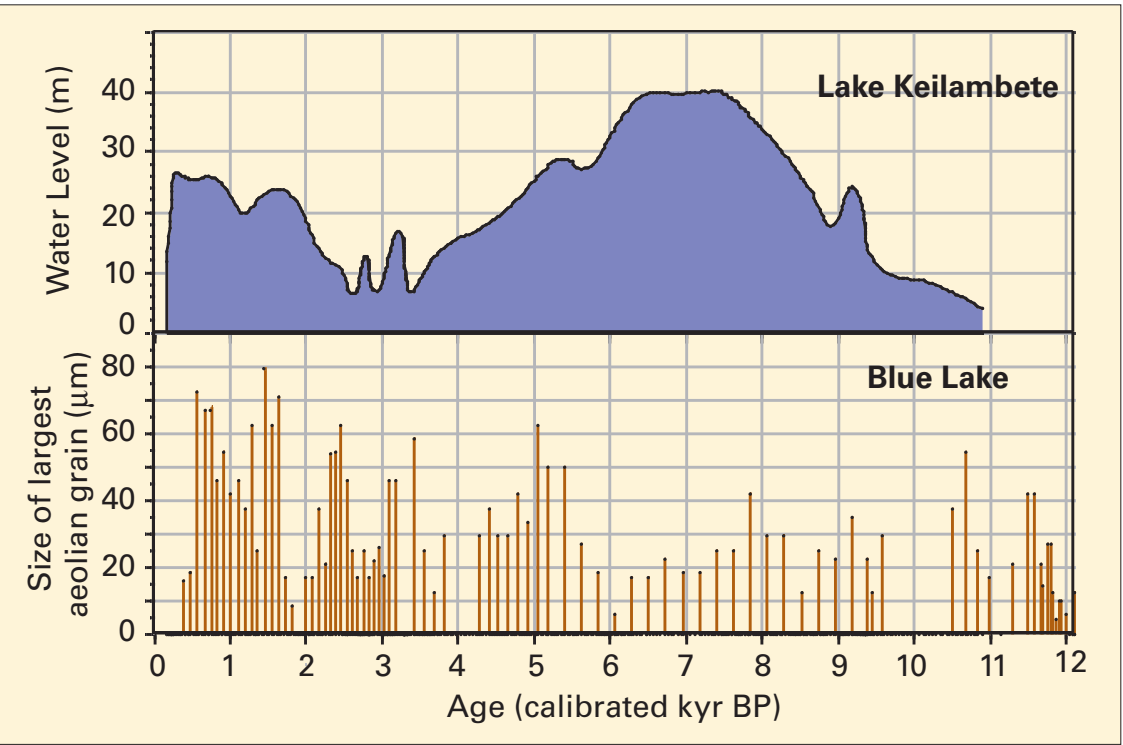

Fig. 2. Aeolian dust and lake level reconstruction from two lakes in southeastern Australia.

part of the core during the last 5 ky signifies a change in oceanic circulation in the region. At present, no pteridophytes grow in northern Australia. We therefore assume that the spores in the core originated in Indonesia or Papua New Guinea and that their presence indicates changes in the Leeuwin Current, which today travels poleward along the coast of Western Australia with an intensity and compare it to the well-documented record of lake-level changes from the crater in Lake Keilambete located to the southwest (map, Figure 2). Size analysis of the largest aeolian quartz grains found in a core from Blue Lake points to an intensification of winds or storm frequency over the last 5 ky, a period when lake levels in Lake Keilambete were both relatively low (Bowler, 1981) and variable.

The studies presented here indicate an onset of the Australian monsoon 14 thousand years ago. Furthermore, millennial scale variability in Australian climate is shown to have occurred subsequent to the Last Glacial Maximum.

\section{Acknowlegements}

Tim Barrows for SST reconstructions, Kyoma Takahashi for nannoplankton data and Sander van der Kaars for pollen data.

\section{REFERENCES}

Barrows, T. T. et al., 2001, Quat. Res, 55, 179-189. Bowler, J. M., 1981, Hydrobiologia, 82, 431-444. Miller, G. H. et al., 1997, Science, 385, 241-244. Pearce, A. F. \& Phillips, B. F., 1988, J. cons. int. explor. mer 45, 13-21.

Stanley, S. \& De Deckker, P., in press, J. Paleolim.

\section{An 8,000 Year Multi-proxy Record from Lake Issyk-Kul, Kyrgyzstan}

\author{
K.A. Rasmussen 1, R.D. Ricketts 2 , T.C. Johnson 2, V.V. Romanovsky3, 0.M. Grigina4 \\ 1 Department of Paleobiology, Smithsonian Institution, USA. krasmus@aol.com \\ 2 Large Lakes Observatory, University of Minnesota, USA. ricketts@d.umn.edu. tcj@d.umn.edu \\ 3 Kyrgyz Institute of Water Problems and Hydropower, Kyrgyzstan. \\ 4 Department of Geology and Mineralogy, Moscow State University, Russia
}

Lake Issyk-Kul is a deep, closedbasin lake nestled at $1607 \mathrm{~m}$ asl in the Tien Shan mountains of Kyrgyzstan $\left(42^{\circ} 30-43^{\circ} 20 \mathrm{~N}\right.$ and $76^{\circ} 10-78^{\circ} 20$ E) - a valuable site along the PAGES PEP II transect from which to extract paleoclimatic information. Its deep continental interior location offers a unique opportunity to study the paleoclimate history of a climatically sensitive "amplifier" lake situated in the heart of the Asian continent positioned relatively far from monsoonal influences to the south.

The lake resides in a semi-arid continental setting between two Alpine-glaciated mountain ranges (Figure 1). Local meteorological data suggest that moisture delivered to the basin (about $100-400 \mathrm{~mm}$ / $\mathrm{yr}$ ) is mostly derived from the west. Approximately $10 \%$ of the 4.6 million inhabitants of Kyrgyzstan depend upon Issyk-Kul for their livelihood. Issyk-Kul has a long history of large-scale and ongoing lake-level changes. Since at least 1856 the basin has been closed and over the same period the level has declined about 12 meters (Semenov, 1858). Considerable present-day concern arises from the recognition that the lake level has declined about 3 meters since 1926 .

Little was known of Lake Issyk-Kul prior to the mid-1990's (Rasmussen and Romanovsky, 1995). Our goal over the past 4 years has been to reconstruct the Late Quaternary history of Lake Issyk-

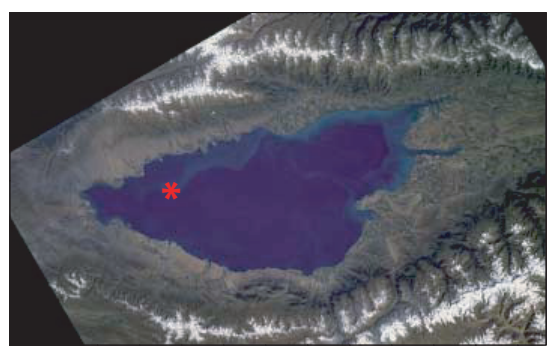

Fig. 1. Aerial view of Lake Issyk-Kul from the space shuttle (STS047-077-082, Sept 1992) showing its position amidst Alpineglaciated highlands of the Tien Shan. The Asterisk indicates the west-central location of core IK97-10P in $230 \mathrm{~m}$ water depth.

Kul. Initial results of this continuing project are reported here.

We recovered eleven piston cores from Lake Issyk-Kul in 1997. IK97-10P was selected for detailed analyses of AMS-radiocarbon age (larger ostracodes), grain size (bulk, and also carbonate-free detrital mud fraction only), sand-fraction 